\title{
TINGKAT KEPUASAN MAHASISWA TINGKAT III \\ PROGRAM STUDI DIPLOMA TIGA KEPERAWATAN \\ TERHADAP LINGKUNGAN PEMBELAJARAN KLINIK \\ DI SEKOLAH TINGGI ILMU KESEHATAN PANTI RAPIH \\ YOGYAKARTA
}

\section{Gabriella Andrea Pranata ${ }^{1}$, Gaudensius Hengky Togand², Bernadetta Eka Noviati $^{3}$}

${ }^{1}$ STIKes Panti Rapih Yogyakarta, Jl. Tantular No 401, Condongcatur, Depok, Sleman, Yogyakarta, email: gabriellandrea2000@gmail.com

${ }^{2}$ STIKes Panti Rapih Yogyakarta, Jl. Tantular No 401, Condongcatur, Depok, Sleman, Yogyakarta, email: togandrsfatima@gmail.com

${ }^{3}$ STIKes Panti Rapih Yogyakarta, Jl. Tantular No 401, Condongcatur, Depok, Sleman, Yogyakarta, email: eka.vie@gmail.com

\begin{abstract}
ABSTRAK
Latar Belakang: Dalam dunia pendidikan keperawatan, pembelajaran klinik merupakan salah satu upaya untuk membantu mahasiswa dalam proses perubahan menjadi perawat yang profesional. Mahasiswa D3 Keperawatan merupakan perawat vokasi dengan pembelajaran teori $40 \%$ dan pembelajaran klinik $60 \%$.
\end{abstract}

Tujuan: Untuk mengetahui tingkat kepuasan mahasiswa tingkat III Program Studi Diploma Tiga Keperawatan terhadap lingkungan pembelajaran klinik di Rumah Sakit.

Metode: Penelitian ini merupakan penelitian deskriptif kuantitatif pendekatan survey dengan teknik samplingtotal sampling dengan jumlah responden sebesar 84. Instrumen penelitian menggunakan instrumen baku (Clinical Learning Environment, Supervision And Nurse TeacherCles + T) yang dialih bahasakan oleh Puji Priyanti \& Naharian(2016), dengan hasil uji validitas instrumen mengunakan PCA (Principal Component Analysis) dengan N=46, uji reliability dengan Cronbach alpha, hasil eigenvalue dan explanation percentage diperoleh $67 \%$, maka dengan demikian instrumen tersebut dinyatakan valid dan reliable.

Hasil: Hasil penelitian didapatkan bahwa sebanyak 81 mahasiswa atau 96.4\% mahasiswa Tingkat III Program Studi Diploma Tiga Keperawatan, menyatakan puas terhadap lingkungan pembelajaran klinik dan sebagian kecil responden yaitu sebanyak 3 mahasiswa atau3,6\% mahasiwa menyatakan tidak puas. 
Gabriella Andrea Pranata, Gaudensius Hengky Togand, Bernadetta Eka Noviati

Tingkat Kepuasan Mahasiswa Tingkat III Program Studi Diploma Tiga Keperawatan

Terhadap Lingkungan Pembelajaran Klinik di Sekolah Tinggi Ilmu Kesehatan Panti

Rapih Yogyakarta

Simpulan: 96.4\% mahasiswa Tingkat III Program Studi Diploma Tiga Keperawatan, menyatakan puas terhadap lingkungan pembelajaran klinik dan sebagian kecil $(3,6 \%)$ menyatakan tidak puas. Dengan demikian diharapkan institusi mengadakan evaluasi dan perbaikan secara terus menerus sehingga kepuasan pembelajaran klinik tercapai.

Kata kunci: kepuasan, lingkungan, pembelajaran klinik

\begin{abstract}
Introduction : In nursing education, clinical learning is an effort to assist students in the change process to become a professional nurses. Students of Diploma Nursing Program are vocational nurses with $40 \%$ theory learning and $60 \%$ clinical learning.
\end{abstract}

Objective: This research aims to find out the level of satisfaction of Grade III Students Of Diploma Nursing Program about the clinical learning environment in the college of Health Science Panti Rapih Yogyakarta.

Methode: This research is a type of descriptive quantitative with a survey approach, which uses a total population sampling. The questionnaire given was obtained from Priyanti \& Nahariani, 2016 with the title Scale of Clinical Learning Environment Evaluation, Clinical Learning Environment, Supervision And Nurse Teacher - (Cles + T) (Saarikoski \& Leino-Kilpi 2008) Language Version. Result of S-CVI $=0.9405$. Validity analysis was tested using PCA (Principal Component Analysis) with $\mathrm{N}=46$. Reliability was tested using Cronbach alpha. The results of the eigenvalue and explanation percentage were $67 \%$, it is concluded that the eigenvalue of the factors in CLES $+\mathrm{T}$ has been fulfilled. Cronbach alpha was obtained for 0.786 .

Result: Based on the results of the study which is conducted on October 202020 , it was found that students of Grade III Diploma Nursing Program, with totally 84 respondents, most of them expressed satisfaction with the clinical learning environment as many as 81 respondents with a percentage of $96.4 \%$ and a small proportion were not satisfied as many as 3 respondents with a percentage of $3.6 \%$.

Conclusion: Most of students (96,4\%) expressed satisfaction with the clinical learning environment and a small proportion $(3,6 \%)$ were not satisfied. Therefore, expected that the institution will conduct evaluation and improvement continuously with the result that the clinical learning satisfaction is reached.

Keywords: satisfaction, environment, clinical learning. 


\section{PENDAHULUAN}

Dalam dunia pendidikan keperawatan, pembelajaran klinik merupakan salah satu upaya untuk membantu mahasiswa dalam proses perubahan menjadi perawat yang profesional. Upaya menghasilkan perawat yang profesional melalui pendidikan yang sudah ditempuh pada Perguruan Tinggi Keperawatan yakni dalam proses pembelajaran klnik. Pembelajaran klinik merupakan fokus pembelajaran dan pengajaran yang melibatkan klien atau pasien secara langsung. Pembelajaran klinik merupakan jantung dari segala pendidikan keperawatan.

Pembelajaran klinik keperawatan adalah sebuah perwujudan dari penjabaran pelaksanaan kurikulum pendidikan keperawatan guna membekali para mahasiswa untuk dapat mengaplikasikan ilmunya di masyarakat berdasarkan kompetensi yang dimiliki (Astuti, Kusumawati \& Afandi, 2016).

Kualitas pendidik perawat dianggap penting dalam kaitannya dengan kompetensi perawat pendidik. Pentingnya sebuah kompetensi pembimbing klinik yang berguna dalam memfasilitasi mahasiswa, sehingga perlu diketahui persepsi pembimbing klinik tentang kompetensi yang harus dimiliki untuk dapat melakukan tugasnya dengan baik. Fenomena dalam penerapan metode pembelajaran klinik yang sering ditemui adalah mahasiswa sering tidak bisa mencapai target kompetensi sesuai yang ditargetkan dari standar pendidikan keperawatan (Astuti, et. al., 2016).

Menurut Lovelock dan Wirtz (2011) dalam Dailiati (2018) mengatakan bahwa kepuasan adalah suatu sikap yang diputuskan berdasarkan pengalaman yang didapatkan. Kepuasan merupakan penilaian mengenai ciri atau keistimewaan produk atau jasa, atau produk itu sendiri yang menyediakan tingkat kesenangan konsumen berkaitan dengan pemenuhi kebutuhan konsumsi konsumen. Lupiyoadi (2001) dalam Indrasari (2019) menyebutkan lima faktor utama yang perlu diperhatikan dalam kaitannya dengan kepuasan konsumen antara lain kualitas produk, kualitas pelayanan, emosional, harga, dan biaya

Pada umumnya program kepuasan memiliki beberapa indikator (Tjiptono, 2002) dalam Indrasari (2019) 
Gabriella Andrea Pranata, Gaudensius Hengky Togand, Bernadetta Eka Noviati

Tingkat Kepuasan Mahasiswa Tingkat III Program Studi Diploma Tiga Keperawatan Terhadap Lingkungan Pembelajaran Klinik di Sekolah Tinggi Ilmu Kesehatan Panti Rapih Yogyakarta

yakni kesesuaian harapan, minat berkunjung kembali, kesediaan merekomendasikan. Kotler dalam Tjiptono (2002) dalam Annisa, dkk. (2017) mengidentifikasi empat metode untuk mengukur kepuasan konsumen, yaitu ada sistem keluhan dan saran, ghost shopping, survei kepuasan konsumen dan lost customer analysis. Kualitas pelayanan adalah suatu metode mengukur pelayanan mutu, yang diberikan apakah memberikan kepuasan kepada pemakai. Adapun faktor-faktor kualitas pelayanan yang mempengaruhi kepuasan mahasiswa terhadap pembelajaran klinik.

Menurut Novaryatin, dkk. (2018) ada lima dimensi kualitas jasa untuk melihat kepuasan yang dikenal dengan nama ServQual yaitu untuk menilai pelayanan yang berkualitas maka dapat di gunakan kriteriakriteria atau faktor-faktor antara lain tangible, reliability, responsiveness, assurance dan, empathy. Secara kuantitas perkembangan pendidikan keperawatan di Indonesia berkembang pesat, banyak pendidikan keperawatan yang dibuka baik
Akademi Keperawatan (Akper), Sekolah Tinggi Kesehatan (STIKes), maupun Program Studi Ilmu Keperawatan (PSIK). Pendidikan keperawatan diselenggarakan berdasarkan kebutuhan akan pelayanan keperawatan, seperti yang tercantum dalam UU No. 36 Tahun 2014 tentang Kesehatan Pasal 1 Ayat (1), yang menyebutkan bahwa tenaga kesehatan adalah setiap orang yang mengabdikan diri dalam bidang kesehatan serta memiliki pengetahuan dan/atau keterampilan melalui pendidikan di bidang kesehatan yang untuk jenis tertentu memerlukan kewenangan untuk melakukan upaya kesehatan.

Menurut UU No 12 Tahun 2012 mahasiswa adalah peserta didik pada jenjang Pendidikan Tinggi. Mahasiswa keperawatan adalah peserta didik pada jenjang Pendidikan Tinggi yang mengatur pola tingkah laku manusia dari remaja menuju ke peran sesungguhnya, yakni proses dimana pola pikiran mengarah ke lebih tinggi atau lebih serius dalam menjalani peran yang sedang ditempuh pada pendidikan keperawatan untuk dipersiapkan menjadi seorang perawat yang 
profesional melalui pembelajaran klinik di Intitusinya. Pembelajaran klinik merupakan fokus pembelajaran dan pengajaran yang melibatkan klien secara langsung. Pembelajaran klinik merupakan jantung dari segala pendidikan keperawatan.

Pembelajaran klinik keperawatan adalah sebuah perwujudan dari penjabaran pelaksanaan kurikulum pendidikan keperawatan guna membekali peserta didik untuk dapat mengaplikasikan ilmunya di masyarakat berdasarkan kompetensi yang dimiliki. Pengajaran klinik yaitu penemuan kompleksitas dan kesempurnaan praktek yang akan diajarkan. Dengan kata pembelajaran klinik yang berfokus pada hubungan antara teori dan praktek dapat membantu peserta didik, bukan hanya mengaplikasikan teori tetapi juga menemukan bahwa teori-teori keperawatan dapat timbul dari banyaknya pengalaman klinik (Astuti, et. al., 2016).

\section{Lingkungan pembelajaran} praktek klinik yang kondusif sangat diperlukan. Lingkungan dimana, suasana yang mendukung mahasiswa untuk belajar, mengenali kesalahan yang dilakukan, memberikan dukungan moril secara penuh, sebagai bagian dari proses pembelajaran. Demi terciptanya pembelajaran klinik yang efektif, kesenjangan antara pendidikan akademik dan praktik klinik harus selaras. Tuntutan hubungan yang selaras ini diinterprestasikan dalam pengelolaan praktik pembelajaran klinik sebagi dasar perencanaan dan evaluasi pengalaman belajar klinik (Kurdi, Nahariani \& Priyanti, 2018).

$$
\text { Lingkungan pembelajaran }
$$

praktek klinik yang kondusif sangat diperlukan. Lingkungan dimana, suasana yang mendukung mahasiswa untuk belajar, mengenali kesalahan yang dilakukan, memberikan dukungan moril secara penuh, sebagai bagian dari proses pembelajaran. Demi terciptanya pembelajaran klinik yang efektif, kesenjangan antara pendidikan akademik dan praktik klinik harus selaras. Tuntutan hubungan yang selaras ini diinterprestasikan dalam pengelolaan praktik pembelajaran klinik sebagi dasar perencanaan dan evaluasi pengalaman belajar klinik (Kurdi, dkk., 2018).

Supervisi merupakan bagian dari fungsi directing pengarahan dalam fungsi manajemen yang berperan untuk mempertahankan agar segala kegiatan 
Gabriella Andrea Pranata, Gaudensius Hengky Togand, Bernadetta Eka Noviati

Tingkat Kepuasan Mahasiswa Tingkat III Program Studi Diploma Tiga Keperawatan Terhadap Lingkungan Pembelajaran Klinik di Sekolah Tinggi Ilmu Kesehatan Panti Rapih Yogyakarta

yang telah diprogram dapat mata kuliah Keperawatan Dasar, dilaksanakan dengan baik dan lancar. Semester III dengan mata kuliah KMB Ginting (2020) menyatakan, supervisi I dan II, dan semester IV dengan mata secara langsung memungkinkan kuliah praktik KMB I dan KMB III, manajer keperawatan menemukan semester $\mathrm{V}$ dengan mata kuliah berbagai hambatan dan permasalahan Keperawatan Gerontik dan praktik dalam pelaksanaan asuhan keperawatan di ruangan dengan mencoba memandang secara menyeluruh faktor-faktor yang mempengaruhi dan bersama dengan staf keperawatan untuk mencari jalan pemecahannya.

Untuk mewujudkan mahasiswa menjadi calon perawat yang profesional dibutuhkan pengembangan proses pembelajaran klinik. Berdasarkan hal tersebut, sebagian besar yang memiliki peran besar adalah pembimbing dan metode pembelajaran yang digunakan. Sehingga pembimbing harus memberikan inovasi dalam proses pembelajaran.

Dalam pedoman pendidikan STIKes Panti Rapih, Program Studi Diploma Tiga Tingkat Tiga menjalankan pembelajaran klinik sebanyak 5 (lima) kali di rumah sakit yang terdiri dari: Semester II dengan KMB II, semester VI dengan mata kuliah Praktik KGD, Praktik Keperawatan Anak, Praktik Keperawatan Maternitas, Praktik Keperawatan Jiwa, Keperawatan Keluarga dalam Komunitas, dan Praktek Komprehensif.

Menurut peneliti setelah dilakukan studi pendahuluan ditemukan fenomena yang terjadi pada mahasiswa Sekolah Tinggi Ilmu Kesehatan Panti Rapih saat melaksanakan pembelajaran klinik yaitu pembimbing klinik dirasakan oleh mahasiswa belum secara optimal memberikan bimbingan kepada mahasiswa dikarenakan kesibukan pembimbing. Pembimbing akademik (dosen) juga belum secara optimal memberi bimbingan klinik di lahan praktik. Perbedaan sarana dan prasarana pendukung praktik antara fasilitas laboratorium dan di lahan praktik klinik, serta jumlah pasien 
maupun jumlah kompetensi yang akan di ambil kurang memadai, sehingga terjadi banyaknya mahasiswa melaksanakan tambah hari untuk mencapai target kompetensi yang belum tercapai dari standar pendidikan keperawatan.

Memperhatikan hal-hal tersebut, diperlukan penelitian lanjut untuk mengetahui kepuasan mahasiswa terhadap lingkungan pembelajaran klinik di Rumah Sakit.

\section{METODE PENELITIAN}

Penelitian menggunakan metode deskriptif kuantitatif melalui pendekatan survei. Instrumen ini terdiri dari 34 pernyataan yang terbagi dalam 5 sub dimensi, yaitu: suasana strategi pembelajaran (pedagogi) dibangsal (9 pernyataan), hubungan supervisi (8 pernyataan), gaya kepemimpinan kepala ruangan/manajer bangsal (4 pernyataan), tempat pelayanan keperawatan (4 pernyataan), dan peran dosen perawat ( 9 pernyataan) (Priyanti \& Nahariani, 2016).

Instrumen penelitian
mengunakan instrumen baku
(Clinical Learning Environment,
Supervision And Nurse Teacher -

Cles $+T$ ) yang dialih bahasakan oleh Priyanti \& Naharian (2016), uji validitas instrumen mengunakan PCA (Principal Component Analysis) dengan $\mathrm{N}=46$, hasil S-CVI $=0.9405$ uji reliabiliti dengan Cronbach alpha sebesar 0.786, Hasil eigenvalue dan explanation percentage diperoleh $67 \%$, maka dengan demikian instrumen tersebut dinyatakan valid dan reliabel.

Pengambilan data penelitian dengan menggunakan kuesioner melalui google form kepada seluruh mahasiswa tingkat tiga Prodi Diploma Tiga Keperawatan. Pengambilan data dilakukan selama satu bulan dimulai 24 Oktober 2020 dan berakhir pada tanggal 7 November 2020. Analisis data dalam penelitian ini dengan menggunakan analisis univariat untuk melihat distribusi frekuensi dan presentase dari variabel yang diteliti (Budiana, 2011 dalam Mufidah, F, 2019).

\section{HASIL DAN PEMBAHASAN}

Tabel 1.

Tabel karakteristik responden

\begin{tabular}{lll}
\hline \multicolumn{1}{c}{ Karakteristik } & F & \% \\
\hline Laki-laki & 16 & $19,04 \%$ \\
\hline Perempuan & 68 & $80,96 \%$ \\
\hline \multicolumn{1}{c}{ Total } & 84 & $100 \%$ \\
\hline$\leq 30$ tahun & 23 & $27,3 \%$ \\
\hline$\leq 20$ tahun & 61 & $72,7 \%$ \\
\hline
\end{tabular}


Gabriella Andrea Pranata, Gaudensius Hengky Togand, Bernadetta Eka Noviati

Tingkat Kepuasan Mahasiswa Tingkat III Program Studi Diploma Tiga Keperawatan Terhadap Lingkungan Pembelajaran Klinik di Sekolah Tinggi Ilmu Kesehatan Panti Rapih Yogyakarta

\begin{tabular}{ccc}
\hline Total & 84 & $100 \%$ \\
\hline IIIA D3 Keperawatan & 45 & $53,5 \%$ \\
\hline IIIB D3 Keperawatan & 39 & $46,5 \%$ \\
\hline Total & 84 & $100 \%$
\end{tabular}

Sumber: Data primer

Berdasarkan tabel diatas tentang karakteristik jenis kelamin responden di STIKes Panti Rapih Yogyakarta menunjukkan bahwa sebagian kecil responden yang berjenis kelamin lakilaki sebanyak 16 responden dengan presentase 19,04\%, dan sebagian besar responden yang berjenis kelamin perempuan sebanyak 68 responden dengan presentase $80,96 \%$.

Dari responden penelitian di STIKes Panti Rapih Yogyakarta menunjukkan bahwa sebagian kecil responden yang berjenis kelamin lakilaki sebanyak 16 responden dengan presentase 19,04\%, dan sebagian besar responden yang berjenis kelamin perempuan sebanyak 68 responden dengan presentase $80,96 \%$. Karakteristik jenis kelamin menurut penelitian Sukesi (2017) hasil analisis hubungan antara jenis kelamin mahasiswa dengan kepuasan menunjukkan bahwa mahasiswa lakilaki yang mempersepsikan puas lebih tinggi (78\%) dibandingkan wanita (88\%), hasil uji statistik menunjukkan tidak ada hubungan jenis kelamin dengan kepuasan mahasiswa.

Berdasarkan tabel diatas tentang karakteristik umur responden di STIKes Panti Rapih Yogyakarta menunjukkan bahwa lebih dari separuh umur responden yang paling banyak didominasi oleh umur $\leq 20$ tahun sebanyak 61 responden dengan presentase $72,7 \%$, dan kurang dari separuh yaitu umur $\leq 30$ tahun sebanyak 23 responden dengan presentase $23,7 \%$.

Bagian karkteristik umur responden di STIKes Panti Rapih Yogyakarta menunjukkan bahwa lebih dari separuh umur responden yang paling banyak didominasi oleh umur $\leq$ 20 tahun sebanyak 61 responden dengan presentase $72,7 \%$, dan kurang dari separuh yaitu umur $\leq 30$ tahun sebanyak 23 responden dengan presentase $\quad 27,3 \%$. Karakteristik berdasarkan umur menurut penelitian Sukesi (2017) hasil analisis hubungan antara umur dengan kepuasan mahasiswa diperoleh bahwa mahasiswa yang umurnya kurang dari 21 tahun 
yang mempersepsikan puas $83 \%$ dan mahasiswa yang umurnya diatas 21 tahun yang mempersepsikan puas $72 \%$.

Karakteristik kelas responden di STIKes Panti Rapih Yogyakarta menunjukkan bahwa lebih dari separuh responden kelas IIIA D3 Keperawatan sebanyak 45 responden dengan presentase $53,5 \%$, dan kurang dari separuh responden kelas IIIB D3 Keperawatan sebanyak 39 responden dengan presentase $46,5 \%$.

Tabel 2.

Kepuasan mahasiswa terhadap lingkungan pembelajaran klinik

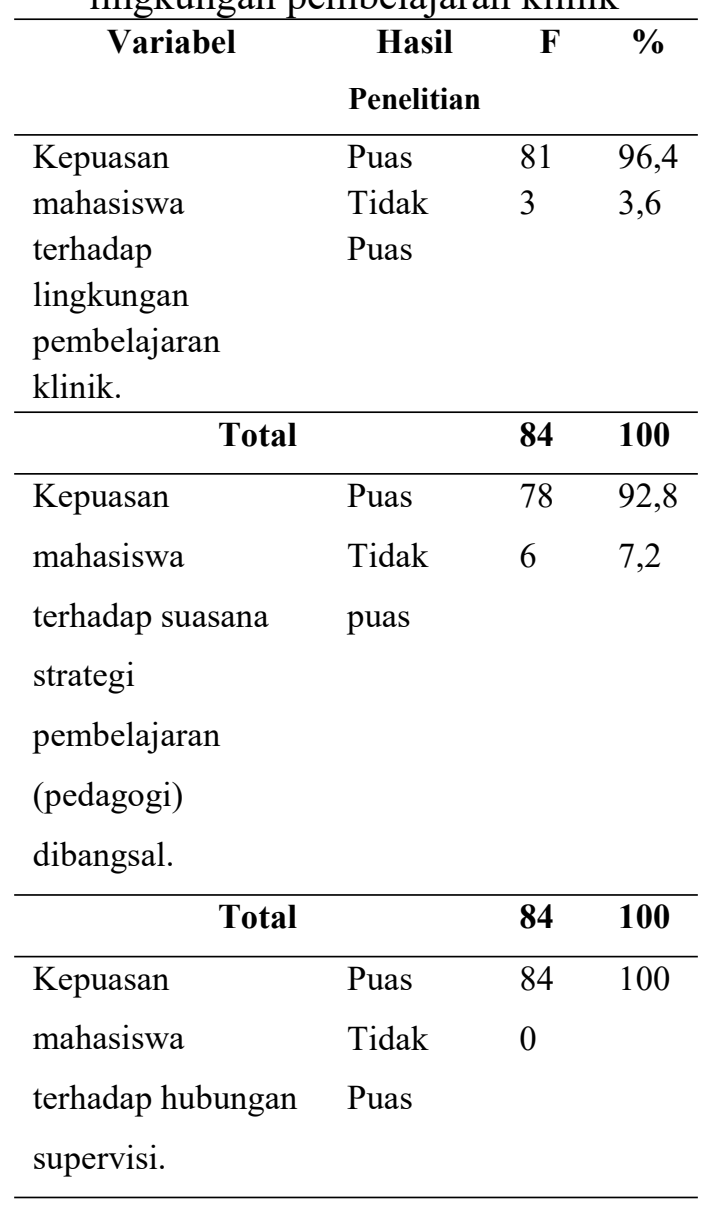

\begin{tabular}{llll}
\hline \multicolumn{1}{c}{ Total } & & $\mathbf{8 4}$ & $\mathbf{1 0 0}$ \\
\hline Kepuasan & Puas & 83 & 98,9 \\
mahasiswa & Tidak & 1 & 1,2 \\
terhadap gaya & Puas & & \\
kepemimpinan & & & \\
kepala ruangan & & & \\
/manajer bangsal. & & & \\
\hline
\end{tabular}

\begin{tabular}{|c|c|c|c|}
\hline Total & & 84 & 100 \\
\hline Kepuasan & Puas & 79 & 94,0 \\
\hline mahasiswa & Tidak & 5 & 6 \\
\hline $\begin{array}{l}\text { terhadap tempat } \\
\text { pelayanan }\end{array}$ & Puas & & \\
\hline keperawatan & & & \\
\hline
\end{tabular}

\begin{tabular}{|c|c|c|c|}
\hline \multicolumn{2}{|c|}{ Total } & 84 & 100 \\
\hline Kepuasan & Puas & 83 & 98,8 \\
\hline mahasiswa & Tidak & 1 & 1,2 \\
\hline terhadap peran & puas & & \\
\hline
\end{tabular}

\begin{tabular}{rrr}
\hline Total & $\mathbf{8 4}$ & $\mathbf{1 0 0}$ \\
\hline Sumber: Data primer &
\end{tabular}

Dari tabel diatas didapatkan bahwa kepuasan mahsiswa terhadap lingkungan pembelajaran klinik sebagian besar responden puas dengan presentase 96,4\% dan sebagian kecil tidak puas dengan presentase $3,6 \%$.

Pembelajaran klinik keperawatan adalah sebuah perwujudan dan dari penjabaran pelaksanaan kurikulum pendidikan keperawatan guna membekali peserta didik untuk dapat mengaplikasikan ilmunya di masyarakat berdasarkan kompetensi yang dimiliki. Pengajaran klinik yaitu penemuan kompleksitas dan 
Gabriella Andrea Pranata, Gaudensius Hengky Togand, Bernadetta Eka Noviati

Tingkat Kepuasan Mahasiswa Tingkat III Program Studi Diploma Tiga Keperawatan Terhadap Lingkungan Pembelajaran Klinik di Sekolah Tinggi Ilmu Kesehatan Panti Rapih Yogyakarta

kesempurnaan praktek yang akan kepuasan mahasiswa terhadap suasana diajarkan. Dengan kata pembelajaran strategi pembelajaran (pedagogi) klinik yang berfokus pada hubungan diperoleh sebagian besar renponden antara teori dan praktek dapat puas dengan presentase $92,8 \%$ dan membantu peserta didik, bukan hanya mengaplikasikan teori tetapi juga sebagian kecil tidak puas dengan presentase $7,2 \%$. Ketidakpuasan menemukan bahwa teori-teori dikarenakan pembimbing kurang keperawatan dapat timbul dari berfokus pada proses pembelajaran banyaknya pengalaman klinik (Astuti, et. a.l, 2016), hal ini menunjukkan bahwa lingkungan pembelajaran praktek klinik yang kondusif sangat diperlukan. Lingkungan dimana, suasana yang mendukung mahasiswa untuk belajar, mengenali kesalahan yang dilakukan, memberikan dukungan moril secara penuh, sebagai bagian dari proses pembelajaran. Demi terciptanya pembelajaran klinik yang efektif, kesenjangan antara pendidikan akademik dan praktik klinik harus selaras. Tuntutan hubungan yang selaras ini diinterprestasikan dalam pengelolaan praktik pembelajaran klinik sebagi dasar perencanaan dan evaluasi pengalaman belajar klinik (Kurdi, dkk., 2018).

Dari hasil penelitian terhadap subvariable pertama mengenai mahasiswa di bangsal. Diharapkan sebelum melakukan pembelajaran klinik mahasiswa mendapatkan arahan mengenai pembelajaran kompetensi yang akan dicapai. Diperlukan juga paparan perlunya kerjasama dalam tim dan saling mengenal satu sama lain. Responden juga menyatakan tidak puas terhadap tempat pelayanan keperawatan karena arus informasi terkait pelayanan terdapat masalah dan pasien tidak menerima pelayanan perawatan secara individu. Harapan pasien dalam pemberian informasi terkait pelayanan diberikan secara singkat dan jelas sehingga pasien mampu mendapatkan pelayanan perawatan yang optimal. Kepuasan mahasiswa terhadap lingkungan pembelajaran klinik dipengaruhi oleh suasana bangsal dapat dianggap sebagai lingkungan belajar yang baik, 
dimana mahasiswa dapat praktek langsung ke pasien sehingga dapat menambah keterampilan dan pengetahuan.

Para pembimbing klinik tidak berasal dari latar belakang pendidik yang menguasai ilmu pedagogik, hal ini sering menjadi kendala ketika melakukan bimbingan kepada mahasiswa diklinik terlebih terkait strategi mengajar, pendampingan mahasiswa di klinik, teknik evaluasi pembelajaran klinik, serta membantu mahasiswa untuk beraktualiasasi diri. Perbedaan metode bimbingan yang diterima oleh mahasiswa di klinik dan kampus kadang menimbulkan persoalan tersendiri bagi mahasiswa. Di kampus mahasiwa lebih fokus pada konsep-konsep yang harus dikuasai oleh seorang calon perawat, saat praktik klinik mahasiswa harus berhadapan dengan pasien yang sesungguhnya. Walaupun di laboratorium keperawatan mahasiswa juga melakukan praktik dengan probandus atau orang yang berperan sebagai pasien, namun hal ini tetap saja berbeda ketika mahasiswa harus berhadapan langsung dengan klien dan keluarga (Ginting, 2020). Sehingga diperlukan suasana yang kondusif dengan menggunakan strategi mengarahkan mahasiswa dengan perawat senior yang berpengalaman sehingga diharapkan mahasiswa dapat mengembangkan kompetensi klinik yang meliputi pengetahuan, keterampilan, nilai-nilai, dan sikap yang diperlukan.

Ketidakpuasan juga didapatkan dari sistem komunikasi andata pembimbing dan mahasiswa. Hal ini sejalan dengan penelitian Rahmi, U, et. al. (2019) menunjukkan bahwa dengan mengarahkan mahasiswa dengan perawat senior yang berpengalaman (preseptorship) sehingga memberikan kepuasaan bagi mahasiswa dalam proses pembelajaran klinik, hal ini dapat terjadi tentunya dengan berbagai faktor yang menjadi pendukung dalam pelaksanaannya, seperti sistem bimbingan yang sudah baku dan juga adanya pelatihan preseptorship yang telah di ikuti oleh para pembimbing klinik sehingga dapat memberikan pelayanan dengan baik dan juga membantu siswa untuk mencapai kompetensi mereka dengan mudah, dan mereka merasa lebih percaya diri selama memberikan asuhan keperawatan kepada pasien. 
Gabriella Andrea Pranata, Gaudensius Hengky Togand, Bernadetta Eka Noviati

Tingkat Kepuasan Mahasiswa Tingkat III Program Studi Diploma Tiga Keperawatan Terhadap Lingkungan Pembelajaran Klinik di Sekolah Tinggi Ilmu Kesehatan Panti Rapih Yogyakarta

Dari tabel diatas variable dan pengarahan perawat senior dan CI ketiga subdimensi kepuasan (Clinical Instructure) Hubungan mahasiswa terhadap hubungan supervisi ditandai dengan rasa percaya supervisi $\quad 100 \% \quad$ responden sehingga dalam melakukan tindakan menyatakan puas. Supervisi mampu terlaksana dengan baik. Hal ini merupakan bagian dari fungsi berbeda dengan pola supervisi menurut directing pengarahan (dalam fungsi penelitian Kurdi, dkk. (2018), manajemen yang berperan untuk terbatasnya jumlah preceptor di klinik, mempertahankan agar segala kegiatan mengakibatkan supervisor yang yang telah diprogram dapat bertugas dalam praktik pembelajaran dilaksanakan dengan baik dan lancar. klinik hanya satu orang untuk satu Supervisi secara langsung kelompok. Terlebih lagi, tingginya memungkinkan manajer keperawatan menemukan berbagai hambatan/ permasalahan dalam pelaksanaan asuhan keperawatan di ruangan dengan mencoba memandang secara menyeluruh faktor-faktor yang mempengaruhi dan bersama dengan staf keperawatan untuk mencari jalan pemecahannya (Ginting, 2020). Sama dalam pelaksanaan tindakan oleh mahasiswa pada lahan praktik diperlukan supervisi untuk memberikan bantuan berupa pengawasan baik secara langsung maupun tidak langsung kepada mahasiswa sehingga mahasiswa yang disupervisi mampu menjalankan beban kerja perawat pelaksana, maka sebagian besar perawat yang bertugas sebagai supervisor adalah manajer bangsal atau kepala ruangan. Menurut Ginting (2020), supervisi dan evaluasi merupakan bagian yang penting dalam manajemen serta keseluruhan tanggung jawab pemimpin. Pemahaman ini juga ada dalam manajemen keperawatan. Untuk mengelola asuhan keperawatan dibutuhkan kemampuan manajemen dari perawat profesional. Oleh karena itu sebagai seorang manajer keperawatan atau sebagai Perawat profesional diharapkan mempunyai kemampuan dalam supervisi dan evaluasi.

tugas dengan baik oleh pengawasan 
Pada subdimensi kepuasan ruangan yang memberikan tanggung mahasiswa terhadap gaya jawab tapi tidak memperhatikan beban kepemimpinan kepala ruangan/manajer bangsal didapatkan sebesar $98,8 \%$ responden menyatakan puas dan $1,2 \%$ responden menyatakan tidak puas. Responden yang tidak puas berpersepsi bahwa manajer bangsal kurang menganggap staf dibangsal sebagai sumber daya utama. Disamping itu, mahasiswa juga tidak menganggap bahwa manajer bangsal adalah anggota tim. Responden juga merasakan tidak ada masukan dari manajer bangsal. Dinyatakan pula bahwa upaya karyawan kurang dihargai maka seharusnya manajer bangsal, perawat pelaksana, dan CI (clinical instructor) menganggap mahasiswa adalah bagian dari tim sehingga mahasiswa mendapat masukan terkait pelaksanaan tindakan dan upayanya dapat dihargai. Pemimpin yang baik adalah pemimpin yang memperhatikan kesejahteraan karyawan atau petugas. Hal tersebut seiring dengan penelitian yang dilakukan oleh Rumondor, M., et al (2019), perawat merasa puas dengan kepemimpinan yang demokratis kepada perawat. Perawat yang tidak puas karna ada kepala kerja yang di imbangi oleh perawat. Gaya kepemimpinan merupakan kepemimpinan yang menghargai sifat dan kemampuan staf, menggunakan kekuasaan posisi untuk mendorong ide dari staf, memberikan informasi seluasluasnya dan pelimpahan sebagian wewenang kepada bawahan, keputusan dibuat secara musyawarah, dan prakarsa dapat datang dari bawahan, pengawasan tidak ketat. Kepuasan mahasiswa terhadap gaya kepemimpinan kepala ruangan/manajer bangsal dipengaruhi kepemimpinan yang menghargai sifat dan kemampuan staf dengan cara upaya masing-masing karyawan dihargai.

Pada subdimensi kepuasan mahasiswa terhadap tempat pelayanan keperawatan didapatkan $\quad 94,0 \%$ responden puas dan $6 \%$ tidak puas. Institusi pendidikan dan lahan praktik keperawatan bertanggungjawab dalam menyiapkan calon perawat. Namun yang terjadi saat ini masih banyak ditemukan kesenjangan antara teori yang diberikan di kelas dengan praktik dalam proses bimbingan di klinik yang diberikan kepada calon perawat atau mahasiswa. Hal ini sering 
Gabriella Andrea Pranata, Gaudensius Hengky Togand, Bernadetta Eka Noviati

Tingkat Kepuasan Mahasiswa Tingkat III Program Studi Diploma Tiga Keperawatan Terhadap Lingkungan Pembelajaran Klinik di Sekolah Tinggi Ilmu Kesehatan Panti Rapih Yogyakarta

menyebabkan mahasiswa sering dibandingkan di lingkungan kampus, mengalami kesulitan dalam dimana sebagian peralatan di RS belum beradaptasi di lahan praktik dikenal oleh mahasiswa, selain itu (Dadgaran, et. al., 2012). peralatan yang tidak sama persis Ketidakpuasan responden didapatkan dengan laboratorium, membuat terhadap filosofi keperawatan bangsal mahasiswa harus beradaptasi terlebih tidak ditetapkan dengan jelas, pasien dahulu. tidak menerima pelayanan secara individu, dan adanya masalah dalam arus informasi terkait dengan pelayanan seharusnya dalam pemberian informasi terakit dengan pelayanan secara singkat dan jelas, serta pasien mampu mendapatkan pelayanan perawatan yang optimal. Hal ini berbeda dengan hasil penelitian Rahmi, et. al. (2019) tentang tingkat kepuasan mahasiswa D3 Keperawatan di Politeknik Kesehatan kota Bandung dalam pembelajaran klinik menunjukkan bahwa 51 responden $(54,8 \%)$ puas) dan 42 responden $(45 \%)$, hal ini menunjukkan masih cukup banyak responden yang belum puas terhadap gedung (tempat praktik), ruangan, kebersihan, kerapian dan kenyamanan dalam pembelajaran klinik.

Kebutuhan mahasiswa dalam pembelajaran klinik lebih komplek

Dari subdimensi kepuasan mahasiswa terhadap peran dosen perawat didapatkan $98,8 \%$ puas dan $1,2 \%$ tidak. Pembimbing/dosen memiliki peran pentin dalam menentukan metode pembelajaran yang digunakan. Dengan demikian pembimbing harus memberikan inovasi dalam proses pembelajaran. Pemilihan strategi atau metode pembelajaran sangat mempengaruhi hasil pembelajaran. Beberapa model pembelajaran klinik telah digunakan untuk mendidik mahasiswa keperawatan seperti model eksperensial, model konferensi praklinik (preconference), konferensi pasca klinik (postconference), umpan balik (peer review), isu (issue) dan multidisiplin, bed site teaching, observasi lapangan, fieldtrip, demonstrasi dan ronde keperawatan. (Patmawati, et.al., 2018). 
Hal tersebut seiring dengan kepuasan mahasiswa terhadap penelitian Putriyanti, et. al. (2019) hubungan supervisi menyatakan semua yang menunjukkan bahwa semua puas dengan presentase $100 \%$. responden memberi jawaban bahwa mereka sangat senang dan puas Subdimensi kepuasan mahasiswa menjalani praktik klinik karena terhadap gaya kepemimpinan kepala pembimbing klinik sangat ruangan/manajer bangsal didapatkan berkompetensi mulai dari pengetahuan pembimbing, sikap pembimbing klinik, keterampilan membimbing di klinik, kemampuan berkomunikasi. Dalam penelitian hal yang sama adalah sikap pembimbing klinik, keterampilan membimbing di klinik dengan dosen perawat dan tim klinik bekerja sama dalam mendukung pembelajaran.

\section{KESIMPULAN DAN SARAN}

\section{Kesimpulan}

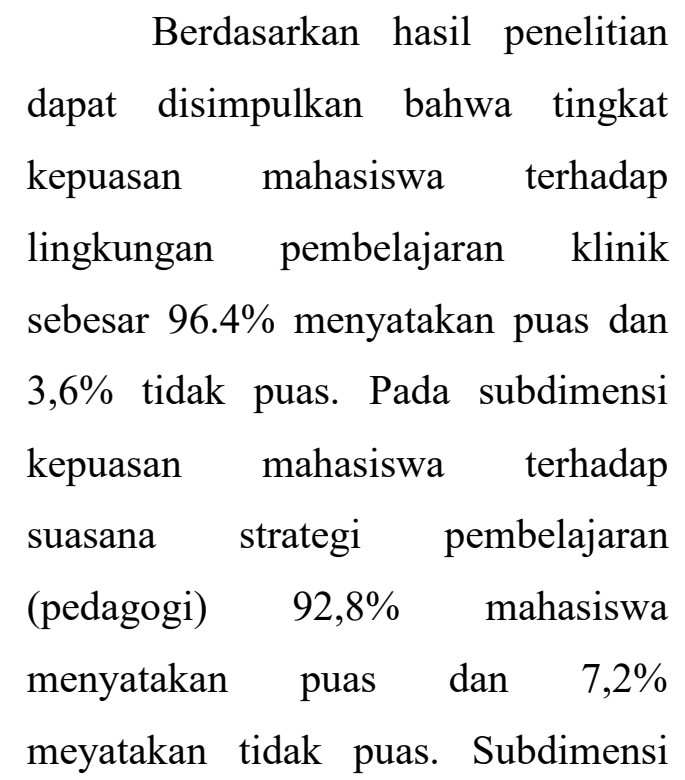
$98,8 \%$ mahasiswa puas dan $1,2 \%$ mahasiswa merasa tidak puas. Pada subdimensi kepuasan mahasiswa terhadap tempat pelayanan keperawatan didapatkan 94,0\% mahasiswa puas dan $6 \%$ mahasiswa tidak puas. Subdimensi kepuasan mahasiswa terhadap peran dosen perawat $98,8 \%$ mahasiswa puas dan $1,2 \%$ mahasiswa menyatakan tidak puas. Dengan demikian dapat disimpulkan bahwa kepuasan mahasiswa tingkat tiga Prodi Diploma Tiga Keperawatan terhadap lingkungan pembelajaran klinik didapatkan sudah sangat baik.

\section{Saran}

Saran untuk peneliti selanjutnya terhadap penelitian yang sejenis adalah untuk dapat mengembangkan metode analisis penelitian yang lebih mendalam. 
Gabriella Andrea Pranata, Gaudensius Hengky Togand, Bernadetta Eka Noviati Tingkat Kepuasan Mahasiswa Tingkat III Program Studi Diploma Tiga Keperawatan Terhadap Lingkungan Pembelajaran Klinik di Sekolah Tinggi Ilmu Kesehatan Panti Rapih Yogyakarta

\section{DAFTAR PUSTAKA}

Annisa, N. N., Setyawan, D., Setyawan,

A. A., \& Susila,

I. S. (2017). Pengaruh Stres Kerja Terhadap Kinerja Karyawan Dengan Kepuasan Kerja Sebagai Variabel Intervening (Doctoral dissertation, Universitas Muhammadiyah Surakarta).

Astuti, V. W., Kusumawati, W., \& Afandi, M. (2016). Kompetensi Pembimbing Klinik dalam Proses Pembelajaran di Klinik. Jurnal Penelitian Keperawatan, 2(2).Doi:

https://doi.org/10.32660/jurnal. v2i2.135.

Dailiati, S. (2018). Kebijakan Retribusi Kebersihan Dalam Meningkatkan Kepuasan Masyarakat.Surabaya:CV.Jak arta.

Dadgaran, I., Parvizy, S., \& Peyrovi, H.(2012). A global issue in nursing students clinical learning: The theory-ractice gap. Procedia Social and Beha vioral Sciences, 47, 1713-1718.

Ginting, D. S. (2020). Supervisi Kepemimpinan Keperawatan Dalam Pengembangan Kompetensi Perawat Dalam Memberikan Pelayanan

\section{Kesehatan}

Keperawatan, (Fakultas Sumatera Utara, Medan).Doi: 10.31219/osf.io/jnu5m.

Ginting, D. S. (2020). Tantangan Manajer Keperawatan Dalam Membimbing Mahasiswa Keperawatan (Fakultas Keperawatan, Universitas Sumatera Utara, Medan).Doi: 10.31219/osf.io/xmf8s.

Indrasari, M. (2019). Pemasaran dan Kepuasan Pelanggan.

Surabaya:Anggota IKAPI

Kurdi, F., Nahariani, P., \& Priyanti, R. P. (2018). Komponen evaluasi lingkungan belajar klinik, supervisi dan dosen perawat. Journal of Health Sciences, 13(1).

Mufidah, F. (2019). Gambaran Pengetahuan Perawat Tentang Demensia Di Puskesmas Kota Bandung (Doctoral dissertation, Universitas Pendidikan Indonesia).

Novaryatin, S., Ardhany, S.D., Aliyah, S.(2018).Tingkat Kepuasan Pasien Terhadap Pelayanan Kefarmasian di RSUD Dr. Murjani Sampit. Borneo Journal of Pharmacy. 1(1): 22-26

Priyanti,P, R., \& Nahariani, P. (2018). Skala Evaluasi Lingkungan Belajar Klinik, Supervisi Dan Dosen Perawat (Clinical 
Learning Environment, Supervision And Nurse Teacher - Cles + T) Versi Bahasa Indonesia: Validitas Dan Reliabilitas. Journal of Health Sciences, 9(2).

Patmawati, T. A., Saleh, A., \& Syahrul, S. (2018). Efektifitas Metode Pembelajaran Klinik Terhadap Kemampuan Berpikir Kritis Dan Kepercayaan Diri Mahasiswa Keperawatan: A Literature Review. Jurnal Keperawatan Muhammadiyah, 3(2).

Putriyanti, C. E., Pamenang, G. U., \& Suwarsono, S. (2019). Pengaruh Pelatihan Perceptorship Terhadap Tingkat Pengetahuan, Sikap Pembimbing Klinik Dan Kepuasan Mahasiswa Dalam Proses Bimbingan Di Klinik. Jurnal Kesehatan, 8(1), 59-68.

Rahmi, U., Putri, S.T., Maiszha, D. (2019). Tingkat Kepuasan Mahasiswa DIII Keperawatan dalam Pembelajaran Klinik. Jurrnal Pendidikan Keperawatan Indonesia 5(2), p. 184-190.Doi 10.17509/jpki.v5i2.18076

Rumondor, M., Gannika, L., \& Bataha, Y. Y. (2019). Gaya Pemimpin Kepala Ruangan Dengan Kepuasaan Perawat. Jurnal Keperawatan, 7 (2).
Solfema, S., Bartin, T., \& Pamungkas, A. H. (2019). Optimalisasi Fungsi Taman Bacaan Masyarakat (TBM) Untuk Meningkatkan Budaya Literasi Didaerah Pedesaan. KOLOKIUM: Jurnal Pendidikan Luar Sekolah, 7(2), 147-153.

Sukesi, N. (2017, February). Hubungan Bimbingan Clinical Instructur dengan Kepuasan Mahasiswa Praktik di RS Permata Medika Semarang. In PROSIDING SEMINAR NASIONAL \& INTERNASIONAL.

Tahlil Teuku, dkk. (2019). Challenges In Nursing Education and Research. Aceh: CRC Press.

Undang Undang Republik Indonesia No 12 tahun 2012 tentang Pendidikan Tinggi [Online] 2019.[dikutip 29 Maret 2020.] www.sumberdaya.ristekdikti.go. id

Undang Undang Republik Indonesia No.36 tahun 2014 tentang Tenaga Kesehatan [Online][dikutip 18 April 2020.]www.ipkindonesia.or.id 